\section{INCREASING ORAL HEALTH AWARENESS}

A final year dental student from at the University of Birmingham has produced an oral cancer pack aimed at increasing awareness of the need for early detection of oral cancer.

Harmeet Gill's elective project involved the production of the Oral Cancer Pack

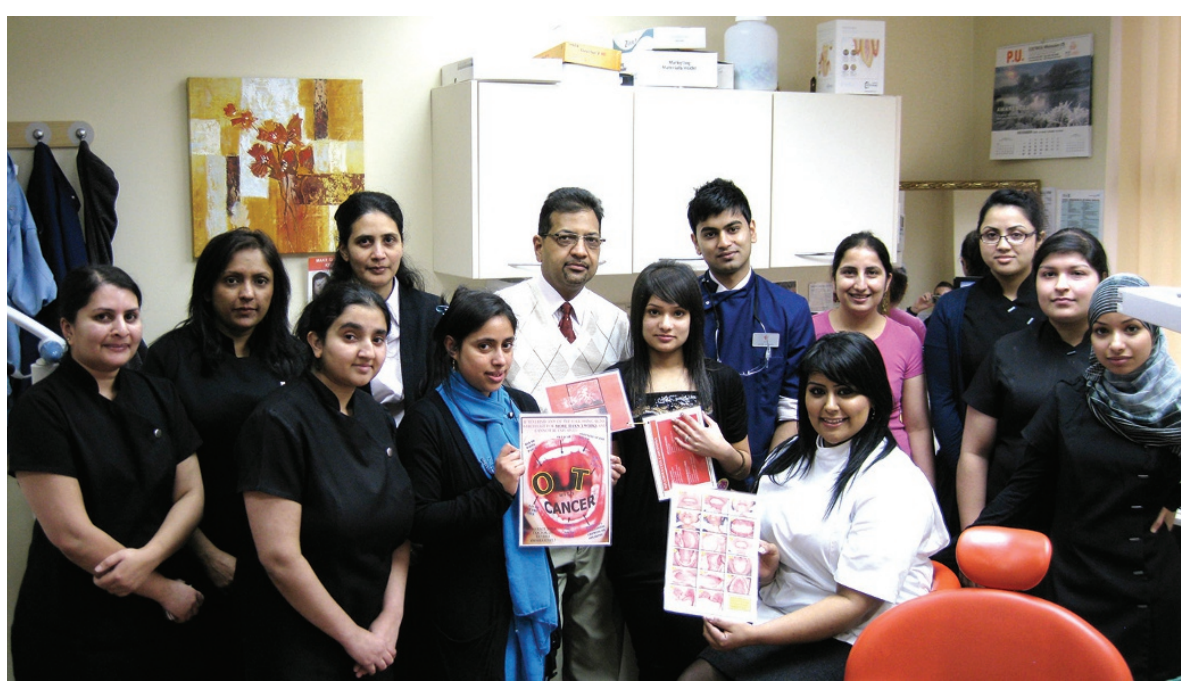

ing patients about risk factors, and a step by step guide to aid the dentist in performing a detailed and comprehensive soft tissue examination.

It is hoped that increased awareness of the need for early detection of oral cancer will improve patient prognosis. The pack also includes an online lecture about oral cancer and a set of laminated picture cue cards for the surgery on pre-malignant conditions and oral squamous cell carcinoma.

As a result of this project, Harmeet went on to win the coveted Best Overall Elective 2010 prize. Subsequent accolades included an article detailing her project being published in local newspaper the Birmingham Post.

The work has also led to Harmeet being invited to give a lecture for South Birmingham PCT dentists on the use of this toolkit as part of their CPD, and she hopes to pursue her interest in the field further once she graduates.

\title{
DENTAL CARE FOR ADULTS WITH COMPLEX NEEDS
}

Suffolk Community Healthcare (SCH) recently became the first provider service in the East of England to recruit a specialist in special care dentistry. Dr Ganga Allen joined SCH's salaried dental team earlier this month. She is one of the country's first such specialists and will provide care to adults with special needs from across Suffolk, holding clinics in Bury St Edmunds, New market and Haverhill.

Dr Allen will support SCH's existing salaried dentists, who provide treatment for people with learning or physical disabilities, mental health problems or complex medical conditions.

She will provide an extra level of experience and expertise in the most complex of cases, where patients may need sedation or other cognitive therapies such as acupuncture to help them to relax so that their teeth can be examined and treated.
Jill Scutt, clinical lead with SCH's salaried dental service, said, 'This specialty is very new and has only been

recently introduced and, as such, Ganga is one of just a handful of such specialists in the whole country.'

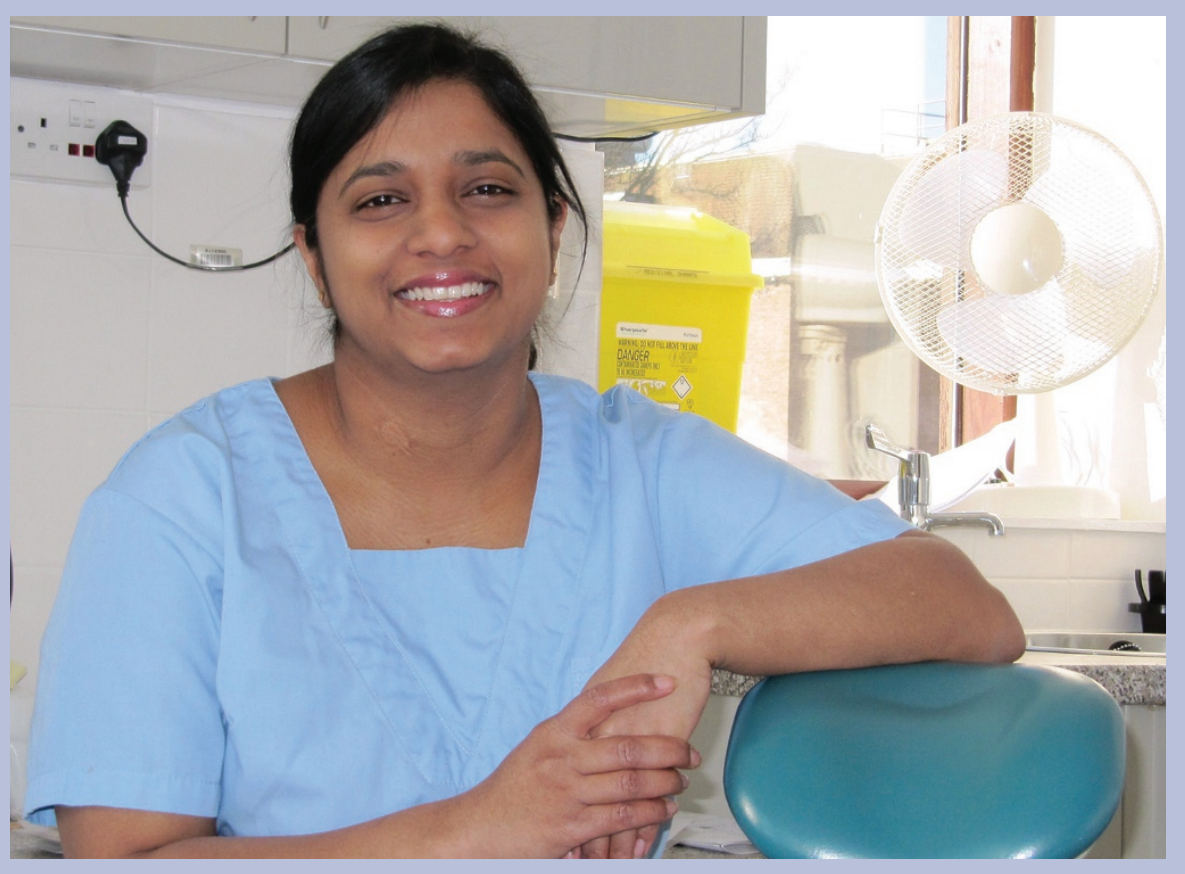

